\title{
Manganese-Catalyzed Electrochemical Deconstructive Chlorination of Cycloalkanols via Alkoxy Radicals
}

Benjamin D. W. Allen, ${ }^{\dagger, \S}{ }^{\circledR 0}$ Mishra Deepak Hareram, ${ }^{\dagger, \S}$ Alex C. Seastram, ${ }^{\dagger}$ Tom McBride, ${ }^{\dagger}$

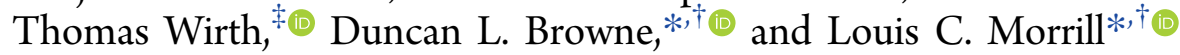

${ }^{\dagger}$ Cardiff Catalysis Institute, School of Chemistry, Cardiff University, Main Building, Park Place, Cardiff CF10 3AT, U.K.

${ }^{\ddagger}$ School of Chemistry, Cardiff University, Main Building, Park Place, Cardiff CF10 3AT, U.K.

\section{Supporting Information}

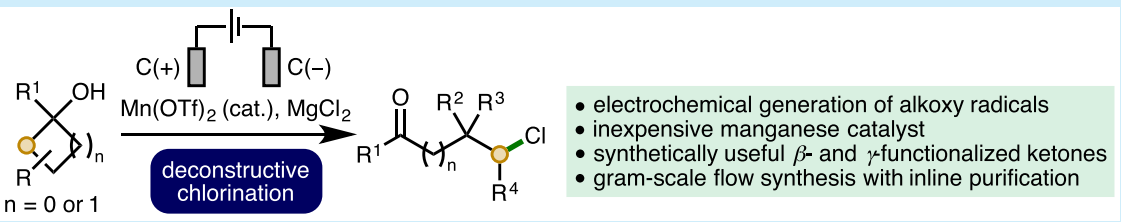

ABSTRACT: A manganese-catalyzed electrochemical deconstructive chlorination of cycloalkanols has been developed. This electrochemical method provides access to alkoxy radicals from alcohols and exhibits a broad substrate scope, with various cyclopropanols and cyclobutanols converted into synthetically useful $\beta$ - and $\gamma$-chlorinated ketones ( 40 examples). Furthermore, the combination of recirculating flow electrochemistry and continuous inline purification was employed to access products on a gram scale.

A lkoxy radicals are highly transient species that exhibit diverse reactivity, including hydrogen atom transfer, ${ }^{1}$ addition to $\pi$ systems, ${ }^{2}$ and $\beta$-scission processes (Scheme $1 \mathrm{~A}$ ). ${ }^{3}$ The generation of alkoxy radicals directly from aliphatic alcohols is challenging, partly due to the high dissociation energy of $\mathrm{RO}-\mathrm{H}$ bonds $(\sim 105 \mathrm{kcal} / \mathrm{mol}){ }^{2 \mathrm{~b}}$ As such,

Scheme 1. Context and Outline of Electrochemical Strategy A) Bond dissociation energy (RO-H) and alkoxy radical reactivity

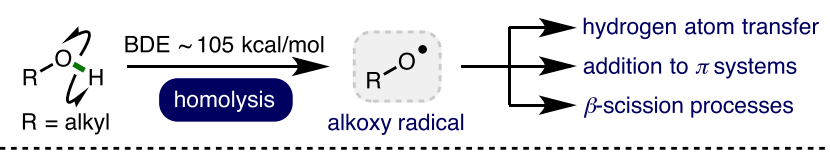

B) Generation of alkoxy radicals
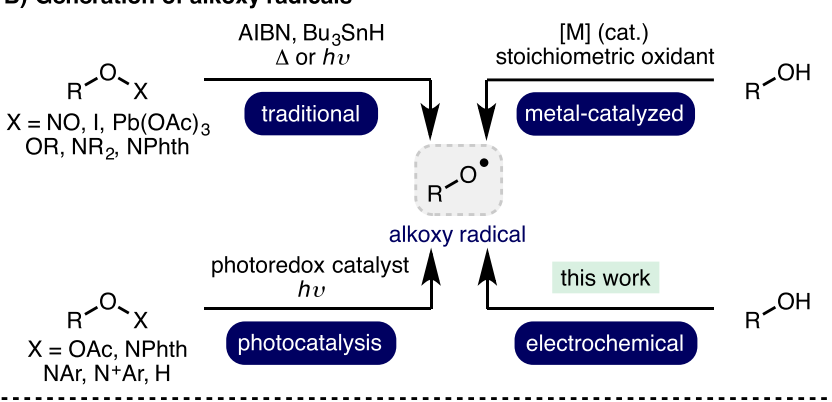

C) Mn-catalyzed electrochemical deconstructive chlorination (this work)

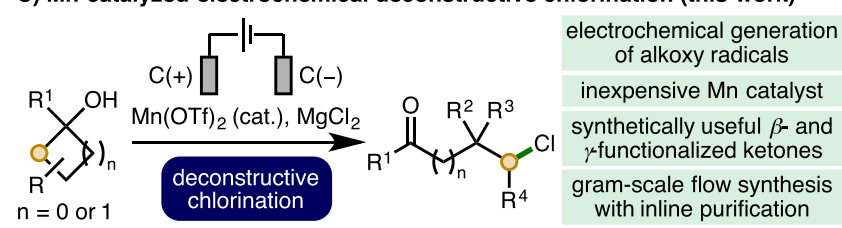

traditional methods for alkoxy radical generation involve the homolysis of weak oxygen-heteroatom bonds within prefunctionalized radical precursors in combination with radical initiators and/or thermal or photochemical activation (Scheme 1B). ${ }^{1,2}$ Alternatively, transition metal salts can be employed in combination with stoichiometric oxidants (e.g., $\mathrm{K}_{2} \mathrm{~S}_{2} \mathrm{O}_{8}$ or hypervalent iodine reagents) for the generation of alkoxy radicals. ${ }^{4}$ Recent advances have developed photocatalytic approaches for alkoxy radical generation employing various radical precursors ${ }^{5}$ including peroxides, ${ }^{6} \mathrm{~N}$-alkoxyphthalimides, ${ }^{7} \quad \mathrm{~N}$-alkoxypyridiniums, ${ }^{8} \quad \mathrm{~N}$-alkoxybenzimidazoles, ${ }^{9} \mathrm{~N}$ alkoxytriazoliums, ${ }^{10}$ and unprotected alcohols. ${ }^{11}$ Despite these important advances, many existing approaches require the use of prefunctionalized substrates, (super)stoichiometric reagents (generating waste/byproducts), and/or precious metal (photo) catalysts.

Organic electrochemistry represents one of the cleanest possible chemical processing technologies, ${ }^{12}$ which has recently undergone a renaissance due partly to the increasing availability of standardized batch and flow electrochemical reactors. ${ }^{13}$ By careful tuning of electrochemical parameters, specific single electron transfer processes can be targeted, accessing powerful radical intermediates. ${ }^{14}$ Despite these characteristics, the development of electrochemical methods for the generation of alkoxy radicals from alcohols has received little attention and remains largely limited to the generation of methoxy radicals, ${ }^{15}$ which requires expensive boron-doped diamond or platinum anodes. ${ }^{16}$ To this end, herein we report

Received: October 16, 2019

Published: November 5, 2019 
the manganese-catalyzed electrochemical deconstructive chlorination of cycloalkanols via alkoxy radical intermediates, ${ }^{17}$ accessing synthetically useful $\beta$ - and $\gamma$-chlorinated ketones (Scheme 1C). Furthermore, by employing microreactor technology and recirculating flow, the electrochemical method can be performed on gram scale, with continuous inline purification incorporated.

To commence our studies, 1-phenylcyclobutan-1-ol 1 was selected as the model substrate (Table 1). After extensive

Table 1. Optimization of Electrochemical Process ${ }^{a}$

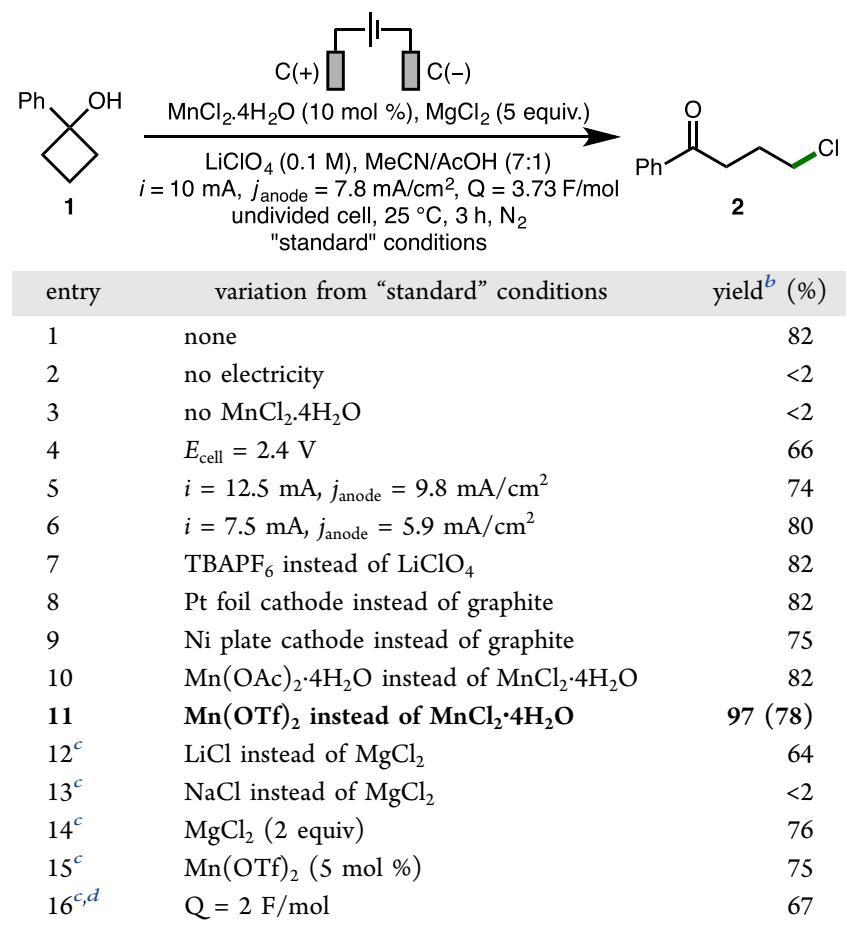

${ }^{a}$ Reactions performed with $0.3 \mathrm{mmol}$ of cyclobutanol 1 using the ElectraSyn 2.0 batch electrochemical reactor. $[1]=0.05 \mathrm{M}$. ${ }^{b}$ Yield after $3 \mathrm{~h}$ as determined by ${ }^{1} \mathrm{H}$ NMR analysis of the crude reaction mixture with 1,3,5-trimethylbenzene as the internal standard. Isolated yield given in parentheses. ${ }^{c} \mathrm{Mn}(\mathrm{OTf})_{2}$ as catalyst. ${ }^{d} 96$ min reaction time.

optimization, ${ }^{18}$ it was found that an electrochemical system composed of $\mathrm{MnCl}_{2} \cdot 4 \mathrm{H}_{2} \mathrm{O}$ (10 mol \%) as catalyst, ${ }^{19} \mathrm{MgCl}_{2}$ (5 equiv) as chloride source, and $\mathrm{LiClO}_{4}$ as supporting electrolyte in $\mathrm{MeCN} / \mathrm{AcOH}(7: 1,[\mathbf{1}]=0.05 \mathrm{M})$ using galvanostatic conditions $\left(i=10 \mathrm{~mA}, j_{\text {anode }}=7.8 \mathrm{~mA} / \mathrm{cm}^{2}, \mathrm{Q}=3.73 \mathrm{~F} / \mathrm{mol}\right)$ and graphite electrodes at $25{ }^{\circ} \mathrm{C}$ for $3 \mathrm{~h}$ under $\mathrm{N}_{2}$, enabled the deconstructive chlorination of $\mathbf{1}$, giving $\gamma$-chlorinated ketone 2 in $82 \%$ NMR yield (entry 1). No conversion occurs in the absence of electricity or the manganese catalyst (entries 2 and $3)$. Employing a constant cell potential $\left(E_{\text {cell }}=2.4 \mathrm{~V}\right)$ or variation of the current $(i=12.5 \mathrm{~mA}$ or $7.5 \mathrm{~mA})$ lowered the NMR yield of 2 (entries 4-6). Employing TBAPF $_{6}$ as electrolyte (entry 7) or substituting the graphite cathode for Pt foil or Ni plate (entries 8 and 9) each had a negligible impact on conversion. However, upon evaluating alternative $\mathrm{Mn}$ (II) salts (entries 10 and 11), it was found that 97\% conversion was obtained using $\mathrm{Mn}(\mathrm{OTf})_{2}$ as catalyst, which was adopted for further optimization. Employing $\mathrm{LiCl}$ or $\mathrm{NaCl}$ as the chloride source was detrimental to conversion, presumably due to decreased solubility in $\mathrm{MeCN} / \mathrm{AcOH}$ (entries 12 and 13). ${ }^{20}$ Gratifyingly, the quantities of $\mathrm{MgCl}_{2}$ and
$\mathrm{Mn}(\mathrm{OTf})_{2}$ could be lowered to 2 equiv and $5 \mathrm{~mol} \%$, respectively, without significant reduction in conversion (entries 14 and 15). A Faradaic efficiency of $67 \%$ was obtained when $2 \mathrm{~F} / \mathrm{mol}$ of charge was passed (entry 16), which indicated that most of the electricity passing through the cell is utilized productively.

The full scope of the electrochemical process was explored starting with the deconstructive chlorination of cyclobutanols to form $\gamma$-functionalized ketones (Scheme 2A). From the outset, it was found that 1-arylcyclobutan-1-ols containing aromatic systems with electron-releasing groups at the 2- or 4positions (e.g., 4- $t \mathrm{Bu}$ ) or extended $\pi$ systems (e.g., 4-Ph) undergo decomposition using the optimized reaction conditions (Table 1, entry 11). This instability was attributed to ionization of the $\mathrm{C}-\mathrm{OH}$ bond in the presence of Brønsted and/or Lewis acids, forming stabilized carbocations that are unproductive for the desired transformation. In such cases, this issue was addressed by employing syringe pump addition of the substrate over $2 \mathrm{~h}$ and using TBAOAc as the supporting electrolyte. With a choice of two suitable reaction conditions in hand, a variety of 1-arylcyclobutan-1-ols were converted to the corresponding $\gamma$-chlorinated ketone products in good to excellent isolated yields (products 2-20). Within the aryl unit, various alkyl and aryl substitution was tolerated at the 4-, 3-, and 2-positions in addition to halides and electronwithdrawing substituents (e.g., 4- $-\mathrm{CF}_{3}$ ). The electrochemical method exhibits good functional group tolerance as demonstrated by the presence of aldehyde, carboxylic acid, methyl ester, primary amide, nitrile, benzylic primary alcohol, and silyl ether functionalities present within products 14-20. A selection of 1-alkylcyclobutan-1-ols were also converted into the corresponding $\gamma$-chlorinated ketones in good isolated yields (products 21-26). Benzo-fused cyclobutanols participated in deconstructive chlorination, giving benzyl chloride products 27-31, including the formation of 7-, 8-, 9-, and 10-membered rings. This strategy was also applied to the formation of disubstituted cycloheptane 32 in $77 \%$ isolated yield. Additional substitution at the 2- and 3-positions of the cyclobutanol was tolerated, accessing $\gamma$-chlorinated ketones 33-35 in high yields. We also investigated the deconstructive chlorination of cyclopropanols (Scheme 2B). Gratifyingly, it was found that a representative selection of 1-arylcyclopropan-1-ols and 1alkylcyclopropan-1-ols could be readily converted to the corresponding $\beta$-chlorinated ketones in good yields (36-39). Additional substitution is tolerated within the cyclopropanol, giving secondary radical derived product $\mathbf{4 0}$ as the major regioisomer. Furthermore, bicyclo[4.1.0] heptan-1-ol was converted to 3-chlorocycloheptan-1-one 41 in $48 \%$ isolated yield. At the current stage of development, the electrochemical method does not tolerate larger ring sizes with reduced ring strain. For example, despite assessing various reaction conditions, 1-phenylcyclopentan-1-ol underwent decomposition, whereas 1-phenethylcyclopentan-1-ol was unreactive. ${ }^{21}$

In order to demonstrate scalability, the batch process was translated to a flow electrochemical setup. ${ }^{22}$ By employing the commercially available Ammonite8 flow electroreactor, ${ }^{23}$ a variety of reaction parameters were evaluated including electrolyte loading, temperature, solvent ratio, residence time, charge, and mixing efficiency (Scheme $2 \mathrm{C}$ ). However, by using $\mathrm{MnCl}_{2} \cdot 4 \mathrm{H}_{2} \mathrm{O}(10 \mathrm{~mol} \%)$ as catalyst, the conversion to 2 could not be increased beyond $20 \%$ using single-pass flow electrochemistry. ${ }^{18}$ The yield was increased by applying the optimized reaction parameters to a recirculating flow electrochemical 
Scheme 2. Substrate Scope: Batch and Flow Electrochemistry*

$$
\begin{aligned}
& \mathrm{C}(+) \Gamma^{\mid \mathrm{I}} \square \mathrm{C}(-)
\end{aligned}
$$

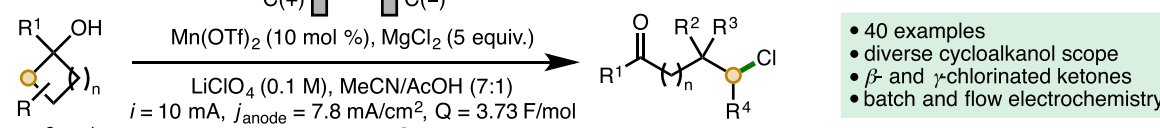

$$
\begin{aligned}
& \mathrm{n}=0 \text { or } 1 \quad \text { undivided cell, } 25^{\circ} \mathrm{C}, 3 \mathrm{~h}, \mathrm{~N}_{2}
\end{aligned}
$$

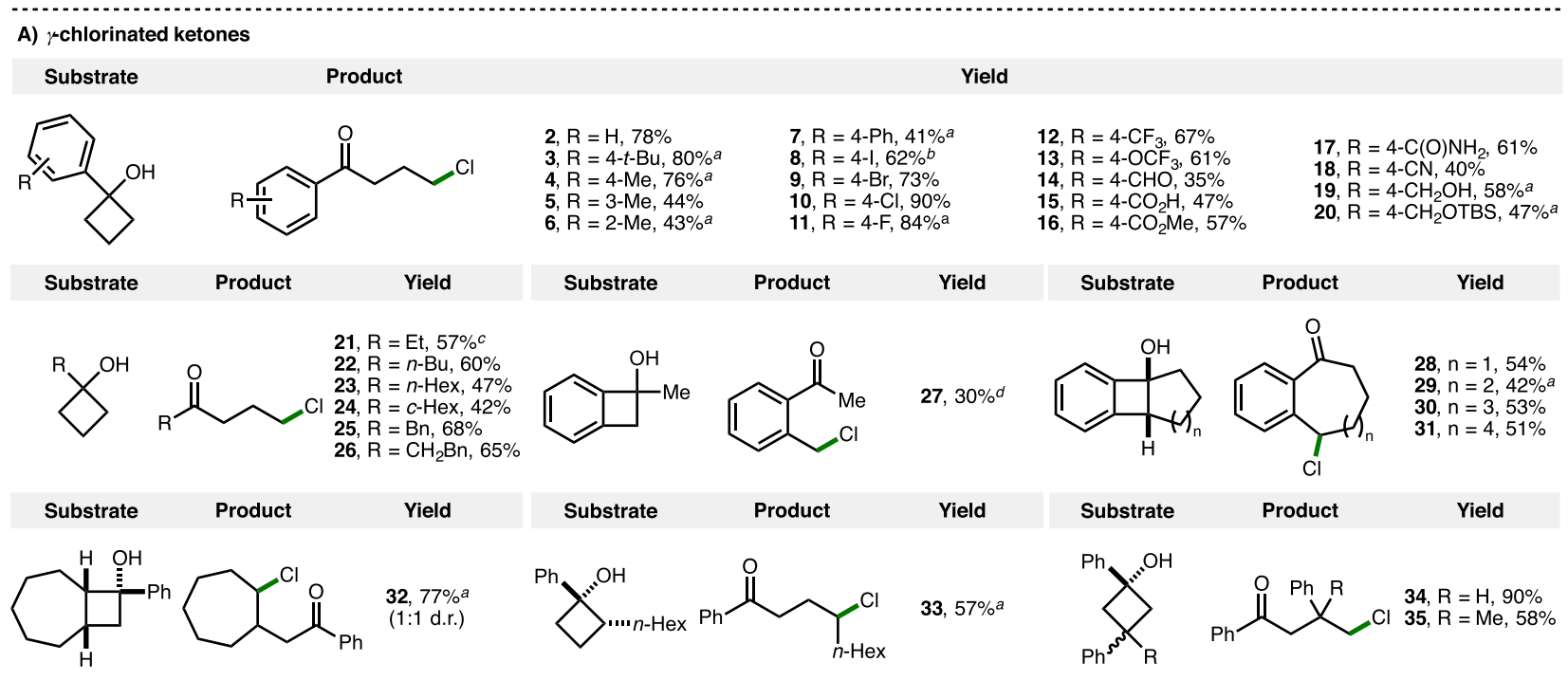

B) $\beta$-chlorinated ketones

\begin{tabular}{ll|lll} 
Substrate & Product & Yield & Substrate & Product
\end{tabular}

\section{マTranslation to Flow}

C) Parameter assessment - single-pass flow electrochemistry $\quad$ :D) Yield optimization - recirculating flow electrochemistry

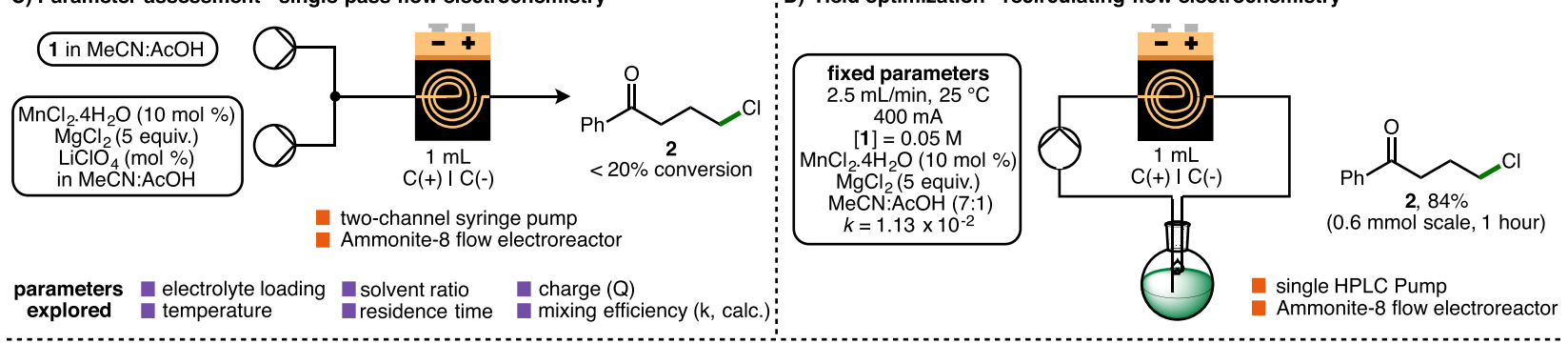

E) Inline purification - recirculating flow electrochemistry + liquid/liquid extraction module

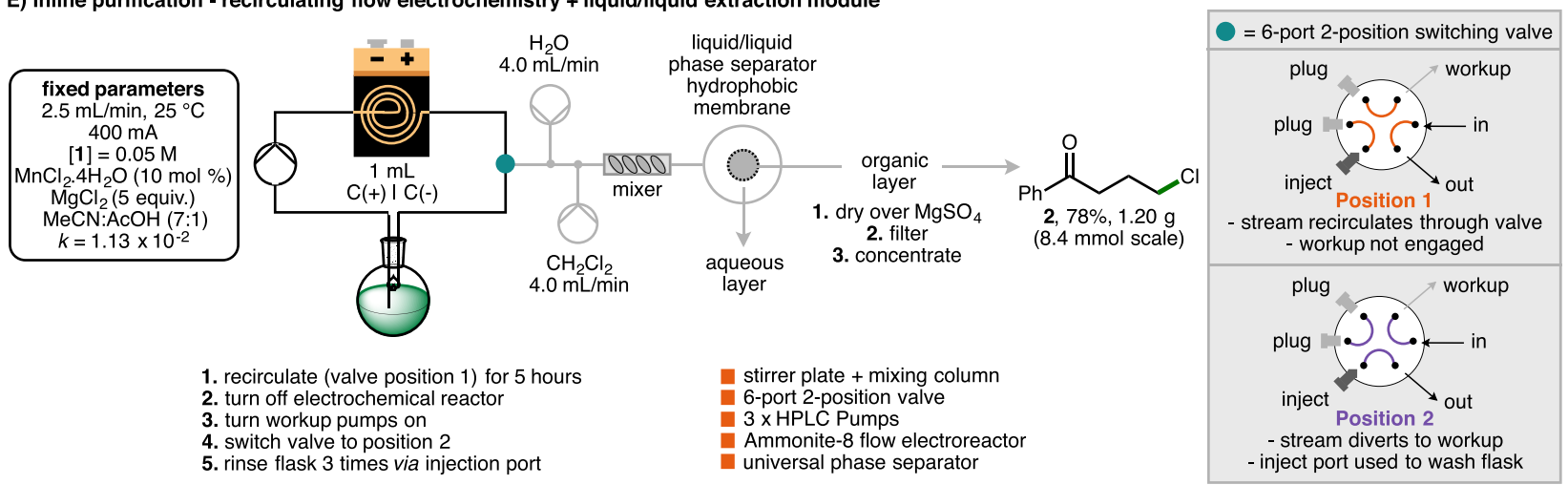

*Reactions performed with $0.3 \mathrm{mmol}$ of cycloalkanol using the ElectraSyn 2.0 batch electrochemical reactor with isolated yields after chromatographic purification quoted unless stated otherwise. ${ }^{a}$ Cycloalkanol was added over $2 \mathrm{~h}$ via syringe pump, TBAOAc $(0.1 \mathrm{M})$ as electrolyte. ${ }^{b}$ TBAOAc $(0.1 \mathrm{M})$ as electrolyte. ${ }^{c}$ Yield as determined by ${ }^{1} \mathrm{H}$ NMR analysis of the crude reaction mixture with $1,3,5$-trimethylbenzene as the internal standard. ${ }^{a} 6 \mathrm{~h}$. 
setup, which provided access to 2 in $84 \%$ isolated yield (Scheme 2D). ${ }^{24}$ Advantageously, due to the decreased distance between the electrodes in flow, a supporting electrolyte was not required. Furthermore, by employing a 6-port 2-position switching valve, the flow could be redirected from recirculation to continuous inline purification (Scheme 2E). Once the electrochemical reaction was complete, the valve was switched from position 1 to position 2 to redirect the flow into the path of workup solvents. The flow was passed through a mixing unit before entering a liquid/liquid phase separator containing a hydrophobic membrane that allowed separation of the organic layer, which was subsequently dried over $\mathrm{MgSO}_{4}$, filtered, and concentrated in vacuo to provide $1.2 \mathrm{~g}$ of product. This flow setup, which combines recirculating flow electrochemistry and continuous inline purification for the first time, might be suitable for $>1 \mathrm{~g}$ scale processing by increasing reactor volume and operation time.

Cyclic voltammetry was employed in order to gain mechanistic insight into the electrochemical process. ${ }^{18}$ In accordance with the literature, ${ }^{19 \mathrm{~d}}$ the combination of $\mathrm{Mn}(\mathrm{OTf})_{2}$ and $\mathrm{MgCl}_{2}$ produced a new quasi-reversible redox event at $\sim 0.8 \mathrm{~V}$ vs $\mathrm{Fc} / \mathrm{Fc}^{+}$, 5 wich provided evidence for the generation of a $\mathrm{Mn}(\mathrm{III}) \mathrm{X}_{2} \mathrm{Cl}$ species from $\left[\mathrm{Mn}(\mathrm{II}) \mathrm{X}_{2} \mathrm{Cl}\right]^{-}$. Furthermore, an increase in the oxidation current was observed upon addition of 1-phenylcyclobutan-1-ol 1, which suggested that $\mathrm{Mn}(\mathrm{III}) \mathrm{X}_{2} \mathrm{Cl}$ is consumed by $\mathbf{1}$. When methyl ether cyclobutane $\mathbf{4 2}$ was employed as the substrate using the standard electrochemical reaction conditions, no $\gamma$-chlorinated ketone 2 was observed, with $82 \%$ starting material recovered (Scheme $3 \mathrm{~A}$ ). This indicated that the proposed $\mathrm{Mn}(\mathrm{III}) \mathrm{X}_{2} \mathrm{Cl}$ species does not promote cyclobutane ring opening in the absence of a hydroxyl functional group. As such, a plausible reaction mechanism initiates with the formation of

\section{Scheme 3. Mechanistic Studies}

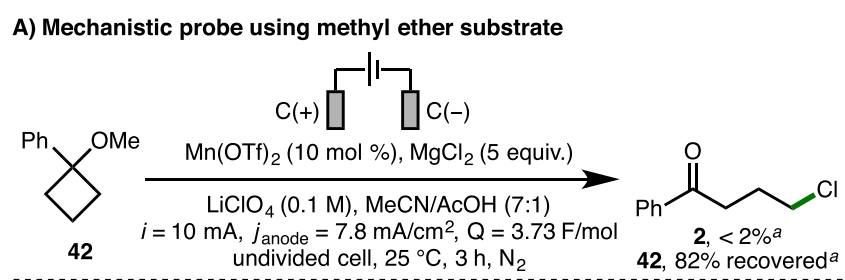

(32, $82 \%$ recovered $^{a}$

B) Plausible reaction mechanism

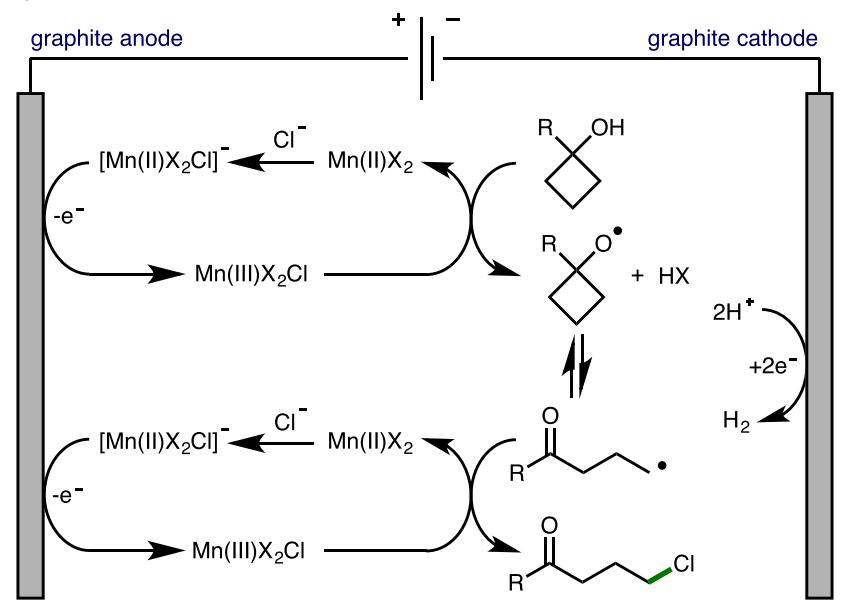

${ }^{a}$ Yield as determined by ${ }^{1} \mathrm{H}$ NMR analysis of the crude reaction mixture with 1,3,5-trimethylbenzene as the internal standard.
$\left[\mathrm{Mn}(\mathrm{II}) \mathrm{X}_{2} \mathrm{Cl}\right]^{-}$from $\mathrm{Mn}(\mathrm{II}) \mathrm{X}_{2}$ and $\mathrm{MgCl}_{2}$, which is oxidized at the anode to form $\mathrm{Mn}(\mathrm{III}) \mathrm{X}_{2} \mathrm{Cl}$ (Scheme 3B). This intermediate undergoes ligand exchange with the cycloalkanol to form a $\mathrm{Mn}$ (III) alkoxide, with subsequent homolysis generating an alkoxy radical, which can undergo reversible $\beta$ scission. Alternatively, the $\mathrm{Mn}(\mathrm{III})$ alkoxide may undergo reversible $\beta$-scission, rather than a free alkoxy radical intermediate. Trapping of the transient primary carboncentered radical with the persistent $\mathrm{Mn}(\mathrm{III}) \mathrm{X}_{2} \mathrm{Cl}$ species forms a new $\mathrm{C}-\mathrm{Cl}$ bond. ${ }^{26}$ Hydrogen gas is generated via proton reduction at the cathode.

In conclusion, we have developed a new electrochemical method for alkoxy radical generation from alcohols and utilized this for the manganese-catalyzed electrochemical deconstructive chlorination of cycloalkanols. The method is applicable across various cyclopropanols and cyclobutanols, accessing a broad range of synthetically useful $\beta$ - and $\gamma$-chlorinated ketones (40 examples). Furthermore, the combination of recirculating flow electrochemistry and continuous inline purification was employed to access products on gram scale. Ongoing studies are focused on further applications of earth-abundant transition metals in synthetic organic electrochemistry, and these results will be reported in due course. ${ }^{27}$

\section{ASSOCIATED CONTENT}

\section{S Supporting Information}

The Supporting Information is available free of charge on the ACS Publications website at DOI: 10.1021/acs.orglett.9b03652.

Optimization data, experimental procedures, characterization of new compounds and spectral data (PDF)

\section{AUTHOR INFORMATION}

\section{Corresponding Authors}

*E-mail: morrilllc@cardiff.ac.uk.

*E-mail: dlbrowne@cardiff.ac.uk.

ORCID $\odot$

Benjamin D. W. Allen: 0000-0002-8536-8677

Thomas Wirth: 0000-0002-8990-0667

Duncan L. Browne: 0000-0002-8604-229X

Louis C. Morrill: 0000-0002-6453-7531

\section{Author Contributions}

${ }^{\S}$ B.D.W.A. and M.D.H. contributed equally to this work. Notes

The authors declare no competing financial interest.

Information about the data that underpins the results presented in this article, including how to access them, can be found in the Cardiff University data catalogue at http://doi. org/10.17035/d.2019.0087324419.

\section{ACKNOWLEDGMENTS}

We gratefully acknowledge the School of Chemistry, Cardiff University, for generous support and the EPSRC for a standard research grant (EP/R006504/1) and doctoral training grants for Ph.D. studentships (A.S., EP/R513003/1; T.M., EP/ N509449/1).

\section{REFERENCES}

(1) (a) Čeković, Ž. Reactions of $\delta$-carbon radicals generated by 1,5 hydrogen transfer to alkoxyl radicals. Tetrahedron 2003, 59, 8073- 
8090. (b) Salamone, M.; Bietti, M. Tuning Reactivity and Selectivity in Hydrogen Atom Transfer from Aliphatic C-H Bonds to Alkoxyl Radicals: Role of Structural and Medium Effects. Acc. Chem. Res. 2015, 48, 2895-2903.

(2) (a) Hartung, J. Stereoselective Construction of the Tetrahydrofuran Nucleus by Alkoxyl Radical Cyclizations. Eur. J. Org. Chem. 2001, 2001, 619-632. (b) Hartung, J.; Gottwald, T.; Špehar, K. Selectivity in the Chemistry of Oxygen-Centered Radicals - The Formation of Carbon-Oxygen Bonds. Synthesis 2002, 1469-1498.

(3) (a) Murakami, M.; Ishida, N. $\beta$-Scission of Alkoxy Radicals in Synthetic Transformations. Chem. Lett. 2017, 46, 1692-1700. (b) Wu, X.; Zhu, C. Recent Advances in Radical-Mediated C-C Bond Fragmentation of Non-Strained Molecules. Chin. J. Chem. 2019, 37, $171-182$.

(4) For selected reviews, see: (a) Ren, R.; Zhu, C. Radical-Mediated Ring-Opening Functionalization of Cyclobutanols: A Shortcut to $\gamma$ Substituted Ketones. Synlett 2016, 27, 1139-1144. (b) Wu, X.; Zhu, C. Recent Advances in Ring-Opening Functionalization of Cycloalkanols by C-C $\sigma$-Bond Cleavage. Chem. Rec. 2018, 18, 587-598.

(5) (a) Jia, K.; Chen, Y. Visible-light-induced alkoxyl radical generation for inert chemical bond cleavage/functionalization. Chem. Commun. 2018, 54, 6105-6112. (b) Guo, J.-J.; Hu, A.; Zuo, Z. Photocatalytic alkoxy radical-mediated transformations. Tetrahedron Lett. 2018, 59, 2103-2111.

(6) DiRocco, D. A.; Dykstra, K.; Krska, S.; Vachal, P.; Conway, D. V.; Tudge, M. Late-Stage Functionalization of Biologically Active Heterocycles Through Photoredox Catalysis. Angew. Chem., Int. Ed. 2014, 53, 4802-4806.

(7) For selected examples, see: (a) Zhang, J.; Li, Y.; Zhang, F.; Hu, C.; Chen, Y. Generation of Alkoxyl Radicals by Photoredox Catalysis Enables Selective $\mathrm{C}\left(\mathrm{sp}^{3}\right)-\mathrm{H}$ Functionalization under Mild Reaction Conditions. Angew. Chem., Int. Ed. 2016, 55, 1872-1875. (b) Wang, C.; Harms, K.; Meggers, E. Catalytic Asymmetric C $\left(\mathrm{sp}^{3}\right)-\mathrm{H}$ Functionalization under Photoredox Conditions by Radical Translocation and Stereocontrolled Alkene Addition. Angew. Chem., Int. Ed. 2016, 55, 13495-13498. (c) Zhang, J.; Li, Y.; Xu, R.; Chen, Y. Donor-Acceptor Complex Enables Alkoxyl Radical Generation for Metal-Free $\mathrm{C}\left(\mathrm{sp}^{3}\right)-\mathrm{C}\left(\mathrm{sp}^{3}\right)$ Cleavage and Allylation/Alkenylation. Angew. Chem., Int. Ed. 2017, 56, 12619-12623.

(8) For selected examples, see: (a) Quint, V.; Morlet-Savary, F.; Lohier, J.-F.; Lalevée, J.; Gaumont, A.-C.; Lakhdar, S. Metal-Free, Visible Light-Photocatalyzed Synthesis of Benzo[b]phosphole Oxides: Synthetic and Mechanistic Investigations. J. Am. Chem. Soc. 2016, 138, 7436-7441. (b) Kim, I.; Min, M.; Kang, D.; Kim, K.; Hong, S. Direct Phosphonation of Quinolinones and Coumarins Driven by the Photochemical Activity of Substrates and Products. Org. Lett. 2017, 19, 1394-1397. (c) Jelier, B. J.; Tripet, P. F.; Pietrasiak, E.; Franzoni, I.; Jeschke, G.; Togni, A. Radical Trifluoromethoxylation of Arenes Triggered by a Visible-Light-Mediated N-O Bond Redox Fragmentation. Angew. Chem., Int. Ed. 2018, 57, 13784-13789. (d) Barthelemy, A.-L.; Tuccio, B.; Magnier, E.; Dagousset, G. Alkoxyl Radicals Generated under Photoredox Catalysis: A Strategy for antiMarkovnikov Alkoxylation Reactions. Angew. Chem., Int. Ed. 2018, 57, 13790-13794. (e) Kim, I.; Park, B.; Kang, G.; Kim, J.; Jung, H.; Lee, H.; Baik, M.-H.; Hong, S. Visible-Light-Induced Pyridylation of Remote $\mathrm{C}\left(\mathrm{sp}^{3}\right)$-H Bonds by Radical Translocation of N-Alkoxypyridinium Salts. Angew. Chem., Int. Ed. 2018, 57, 15517-15522. (f) Bao, X.; Wang, Q.; Zhu, J. Dual Photoredox/Copper Catalysis for the Remote $\mathrm{C}\left(\mathrm{sp}^{3}\right)-\mathrm{H}$ Functionalization of Alcohols and Alkyl Halides by N-Alkoxypyridinium Salts. Angew. Chem., Int. Ed. 2019, 58, 21392143.

(9) Zheng, W.; Morales-Rivera, C. A.; Lee, J. W.; Liu, P.; Ngai, M.-Y. Catalytic C-H Trifluoromethoxylation of Arenes and Heteroarenes. Angew. Chem., Int. Ed. 2018, 57, 9645-9649.

(10) (a) Zheng, W.; Lee, J. W.; Morales-Rivera, C. A.; Liu, P.; Ngai, M.-Y. Redox-Active Reagents for Photocatalytic Generation of the $\mathrm{OCF}_{3}$ Radical and (Hetero)Aryl C-H Trifluoromethoxylation. Angew. Chem., Int. Ed. 2018, 57, 13795-13799. (b) Lee, J. W.; Zheng, W.; Morales-Rivera, C.; Liu, P.; Ngai, M.-Y. Catalytic radical difluor- omethoxylation of arenes and heteroarenes. Chem. Sci. 2019, 10, 3217-3222.

(11) For selected examples, see: (a) Jia, K.; Zhang, F.; Huang, H.; Chen, Y. Visible-Light-Induced Alkoxyl Radical Generation Enables Selective $\mathrm{C}\left(\mathrm{sp}^{3}\right)-\mathrm{C}\left(\mathrm{sp}^{3}\right)$ Bond Cleavage and Functionalizations. J. Am. Chem. Soc. 2016, 138, 1514-1517. (b) Yayla, H. G.; Wang, H.; Tarantino, K. T.; Orbe, H. S.; Knowles, R. R. Catalytic Ring-Opening of Cyclic Alcohols Enabled by PCET Activation of Strong O-H Bonds. J. Am. Chem. Soc. 2016, 138, 10794-10797. (c) Guo, J.-J.; Hu, A.; Chen, Y.; Sun, J.; Tang, H.; Zuo, Z. Photocatalytic C-C Bond Cleavage and Amination of Cycloalkanols by Cerium(III) Chloride Complex. Angew. Chem., Int. Ed. 2016, 55, 15319-15322. (d) Wu, X.; Wang, M.; Huan, L.; Wang, D.; Wang, J.; Zhu, C. Tertiary-AlcoholDirected Functionalization of Remote C $\left(\mathrm{sp}^{3}\right)-\mathrm{H}$ Bonds by Sequential Hydrogen Atom and Heteroaryl Migrations. Angew. Chem., Int. Ed. 2018, 57, 1640-1644. (e) Schwarz, J.; König, B. Visible-light mediated C-C bond cleavage of 1,2-diols to carbonyls by ceriumphotocatalysis. Chem. Commun. 2019, 55, 486-488. (f) Li, G.-X.; Hu, X.; He, G.; Chen, G. Photoredox-mediated remote $\mathrm{C}\left(\mathrm{sp}^{3}\right)-\mathrm{H}$ heteroarylation of free alcohols. Chem. Sci. 2019, 10, 688-693.

(12) For selected recent reviews, see: (a) Yan, M.; Kawamata, Y.; Baran, P. S. Synthetic Organic Electrochemical Methods Since 2000: On the Verge of a Renaissance. Chem. Rev. 2017, 117, 13230-13319. (b) Wiebe, A.; Gieshoff, T.; Möhle, S.; Rodrigo, E.; Zirbes, M.; Waldvogel, S. R. Electrifying Organic Synthesis. Angew. Chem., Int. Ed. 2018, 57, 5594-5619. (c) Kärkäs, M. D. Electrochemical strategies for C-H functionalization and C-N bond formation. Chem. Soc. Rev. 2018, 47, 5786-5865. (d) Moeller, K. D. Using Physical Organic Chemistry To Shape the Course of Electrochemical Reactions. Chem. Rev. 2018, 118, 4817-4833. (e) Tang, S.; Liu, Y.; Lei, A. Electrochemical Oxidative Cross-coupling with Hydrogen Evolution: A Green and Sustainable Way for Bond Formation. Chem. 2018, 4, $27-45$.

(13) (a) Yan, M.; Kawamata, Y.; Baran, P. S. Synthetic Organic Electrochemistry: Calling All Engineers. Angew. Chem., Int. Ed. 2018, 57, 4149-4155. (b) Gütz, C.; Klöckner, B.; Waldvogel, S. R. Electrochemical Screening for Electroorganic Synthesis. Org. Process Res. Dev. 2016, 20, 26-32.

(14) Yan, M.; Lo, J. C.; Edwards, J. T.; Baran, P. S. Radicals: Reactive Intermediates with Translational Potential. J. Am. Chem. Soc. 2016, 138, 12692-12714.

(15) For selected examples, see: (a) Dolson, M. G.; Swenton, J. S. Product and Mechanistic Studies of the Anodic Oxidation of Methoxylated Naphthalenes. The $\mathrm{EEC}_{\mathrm{r}} \mathrm{C}_{\mathrm{p}}$ Mechanism. J. Am. Chem. Soc. 1981, 103, 2361. (b) Carreño, M. C.; Ribagorda, M. Anodic Oxidation of N-Protected 4-Methoxy Anilines: Improved Synthesis of Quinone Imine Acetals. J. Org. Chem. 2000, 65, 1231-1234. (c) Sumi, T.; Saitoh, T.; Natsui, K.; Yamamoto, T.; Atobe, M.; Einaga, Y.; Nishiyama, S. Anodic Oxidation on a Boron-Doped Diamond Electrode Mediated by Methoxy Radicals. Angew. Chem., Int. Ed. 2012, 51, 5443-5446. (d) Yajima, S.; Saitoh, T.; Kawa, K.; Nakamura, K.; Nagase, H.; Einaga, Y.; Nishiyama, S. Asymmetric Induction in cyclohexadienones carrying $\alpha$-D-glucopyranosyl moiety. Tetrahedron 2016, 72, 8428-8435.

(16) For a spiroketal formation, which is proposed to involve anodic oxidation of alkoxides to form alkoxy radicals, see: Markó, I. E. Electrochemical oxidative cyclisation of $\omega$-hydroxy-tetrahydropyrans to spiroketals. Tetrahedron Lett. 2000, 41, 4383-4387.

(17) For a recent review of deconstructive functionalization processes, see: (a) Morcillo, S. P. Radical-promoted C-C bond cleavage: a deconstructive approach for selective functionalization. Angew. Chem., Int. Ed. 2019, 58, 14044. For examples of deconstructive chlorination, see: (b) Fan, X.; Zhao, H.; Yu, J.; Bao, X.; Zhu, C. Regiospecific synthesis of distally chlorinated ketones via C-C bond cleavage of cycloalkanols. Org. Chem. Front. 2016, 3, 227232. (c) Huang, F.-Q.; Xie, J.; Sun, J.-G.; Wang, Y.-W.; Dong, X.; Qi, L.-W.; Zhang, B. Regioselective Synthesis of Carbonyl-Containing Alkyl Chlorides via Silver-Catalyzed Ring-Opening Chlorination of Cycloalkanols. Org. Lett. 2016, 18, 684-687. (d) Huan, L.; Zhu, C. 
Manganese-catalyzed ring-opening chlorination of cyclobutanols: regiospecific synthesis of $\gamma$-chloroketones. Org. Chem. Front. 2016, 3, 1467-1471. (e) Dauncey, E. M.; Morcillo, S. P.; Douglas, J. J.; Sheikh, N. S.; Leonori, D. Photoinduced Remote Functionalisations by Iminyl Radical Promoted C-C and C-H Bond Cleavage Cascades. Angew. Chem., Int. Ed. 2018, 57, 744-748. (f) Roque, J. B.; Kuroda, Y.; Göttemann, L. T.; Sarpong, R. Deconstructive diversification of cyclic amines. Nature 2018, 564, 244-248.

(18) See the Supporting Information for full experimental details.

(19) For examples of Mn-mediated electrochemical reactions, see: (a) Shundo, R.; Nishiguchi, I.; Matsubara, Y.; Hirashima, T. $\mathrm{Mn}^{3+}$ Mediated Coupling-Cyclization of 5-Arylpent-1-enes with Active Methylene Compounds by Electrooxidation. Chem. Lett. 1991, 20, 235-236. (b) Shundo, R.; Nishiguchi, I.; Matsubara, Y.; Hirashima, T. Carbon-Carbon Bond Formation Using Manganese(III) Acetate as an Electrochemical Mediator. Tetrahedron 1991, 47, 831-840. (c) Fu, N.; Sauer, G. S.; Saha, A.; Loo, A.; Lin, S. Metal-catalyzed electrochemical diazidation of alkenes. Science 2017, 357, 575-579. (d) Fu, N.; Sauer, G. S.; Lin, S. Electrocatalytic Radical Dichlorination of Alkenes with Nucleophilic Chlorine Sources. J. Am. Chem. Soc. 2017, 139, 15548-15553. (e) Ye, K.-Y.; Pombar, G.; Fu, N.; Sauer, G.; Keresztes, I.; Lin, S. Anodically Coupled Electrolysis for the Heterodifunctionalization of Alkenes. J. Am. Chem. Soc. 2018, 140, 2438-2441. (f) Ye, K.-Y.; Song, Z.; Sauer, G. S.; Harenberg, J. H.; Fu, N.; Lin, S. Synthesis of Chlorotrifluoromethylated Pyrrolidines by Electrocatalytic Radical Ene-Yne Cyclization. Chem. - Eur. J. 2018, 24, 12274-12279. (g) Merchant, R. R.; Oberg, K. M.; Lin, Y.; Novak, A. J. E.; Felding, J.; Baran, P. S. Divergent Synthesis of Pyrone Diterpenes via Radical Cross Coupling. J. Am. Chem. Soc. 2018, 140, 7462-7465. (h) Fu, N.; Sauer, G. S.; Lin, S. A general, electrocatalytic approach to the synthesis of vicinal diamines. Nat. Protoc. 2018, 13, 1725-1743. (i) Fu, N.; Shen, Y.; Allen, A. R.; Song, L.; Ozaki, A.; Lin, S. Mn-Catalyzed Electrochemical Chloroalkylation of Alkenes. ACS Catal. 2019, 9, 746-754. (j) Zhang, Z.; Zhang, L.; Cao, Y.; Li, F.; Bai, G.; Liu, G.; Yang, Y.; Mo, F. Mn-Mediated Electrochemical Trifluoromethylation/ $\mathrm{C}\left(\mathrm{sp}^{2}\right)-\mathrm{H}$ Functionalization Cascade for the Synthesis of Azaheterocycles. Org. Lett. 2019, 21, 762-766. (k) Lu, L.; Fu, N.; Lin, S. Three-Component Chlorophosphinoylation of Alkenes via Anodically Coupled Electrolysis. Synlett 2019, 30, 11991203. (1) Strehl, J.; Hilt, G. Electrochemical, Mangenese-Assisted Carbon-Carbon Bond Formation between $\beta$-Keto Esters and Silyl Enol Ethers. Org. Lett. 2019, 21, 5259-5263.

(20) The substitution of $\mathrm{MgCl}_{2}$ with other halide salts, namely $\mathrm{KBr}$ or $\mathrm{NaI}$, resulted in $>90 \%$ recovery of cyclobutanol $\mathbf{1}$.

(21) Wilsey, S.; Dowd, P.; Houk, K. N. Effect of Alkyl Substituents and Ring Size on Alkoxy Radical Cleavage Reactions. J. Org. Chem. 1999, 64, 8801-8811.

(22) (a) Yoshida, J.-i.; Nagaki, A. Electrochemical Reactions in Microreactors. In Microreactors in Preparative Chemistry; Reschetilowski, W., Ed.; Wiley-VCH: Weinheim, Germany, 2013; pp 231-242. (b) Folgueiras-Amador, A. A.; Wirth, T. Electrosynthesis in Continuous Flow. Science of Synthesis: Flow Chemistry in Organic Synthesis 2018, 147-189. (c) Laudadio, G.; de Smet, W.; Struik, L.; Cao, Y.; Noël, T. Design and application of a modular and scalable electrochemical flow microreactor. J. Flow Chem. 2018, 8, 157-165. (d) Pletcher, D.; Green, R. A.; Brown, R. C. D. Flow Electrolysis Cells for the Synthetic Organic Chemistry Laboratory. Chem. Rev. 2018, 118, 4573-4591. (e) Atobe, M.; Tateno, H.; Matsumura, Y. Applications of Flow Microreactors in Electrosynthetic Processes. Chem. Rev. 2018, 118, 4541-4572.

(23) Green, R. A.; Brown, R. C. D.; Pletcher, D.; Harji, B. A. Microflow Electrolysis Cell for Laboratory Synthesis on the Multigram Scale. Org. Process Res. Dev. 2015, 19, 1424-1427.

(24) (a) Kawamata, Y.; Vantourout, J. C.; Hickey, D. P.; Bai, P.; Chen, L.; Hou, Q.; Qiao, W.; Barman, K.; Edwards, M. A.; GarridoCastro, A. F.; deGruyter, J. N.; Nakamura, H.; Knouse, K.; Qin, C.; Clay, K. J.; Bao, D.; Li, C.; Starr, J. T.; Garcia-Irizarry, C.; Sach, N.; White, H. S.; Neurock, M.; Minteer, S. D.; Baran, P. S. Electrochemically Driven, Ni-Catalyzed Aryl Amination: Scope, Mechanism, and Applications. J. Am. Chem. Soc. 2019, 141, 6392-6402. (b) Peters, B. K.; Rodriguez, K. X.; Reisberg, S. H.; Beil, S. B.; Hickey, D. P.; Kawamata, Y.; Collins, M.; Starr, J.; Chen, L.; Udyavara, S.; Klunder, K.; Gorey, T. J.; Anderson, S. L.; Neurock, M.; Minteer, S. D.; Baran, P. S. Scalable and safe synthetic organic electroreduction inspired by Li-ion battery chemistry. Science 2019, 363, 838-845.

(25) Sandford, C.; Edwards, M. A.; Klunder, K. J.; Hickey, D. P.; Li, M.; Barman, K.; Sigman, M. S.; White, H. S.; Minteer, S. D. A synthetic chemist's guide to electroanalytical tools for studying reaction mechanisms. Chem. Sci. 2019, 10, 6404-6422.

(26) (a) Studer, A. The Persitent Radical Effect in Organic Synthesis. Chem. - Eur. J. 2001, 7, 1159-1164. (b) Fischer, H. The Persistent Radical Effect: A Principle for Selective Radical Reactions and Living Radical Polymerizations. Chem. Rev. 2001, 101, 35813610.

(27) A prior version of the present article was deposited as a preprint on ChemRxiv: Allen, B. D. W.; Hareram, M. D.; Seastram, A. C.; McBride, T.; Wirth, T.; Browne, D. L.; Morrill, L. C. ManganeseCatalyzed Electrochemical Deconstructive Chlorination of Cycloalkanols via Alkoxy Radicals. ChemRxiv 2019. DOI: 10.26434/ chemrxiv.9275441.v1. 